\title{
AUTENTICIDADE E CONSUMO DE ROCK CLÁSSICO: UMA NETNOGRAFIA NO FACEBOOK ${ }^{1}$
}

\author{
Flávio Medeiros Henriques ${ }^{2}$ \\ Severino Joaquim Nunes Pereira ${ }^{3}$
}

http://dx.doi.org/10.1590/1413-2311.160.61191

\section{RESUMO}

Na sociedade contemporânea, vários movimentos têm ou tiveram no consumo de música uma das principais formas de expressar seus valores, ideologias e descontentamentos, sendo que o rock merece destaque nesse sentido, pois sua própria origem se deu como forma de contestação social. Assim, o objetivo deste trabalho foi investigar como fãs de rock clássico constroem e expressam significados de autenticidade por meio da participação em grupos do Facebook sobre rock. Para isso, foi realizada uma netnografia em dois grupos do Facebook sobre rock clássico durante 12 meses, além de 11 entrevistas em profundidade junto a usuários destes grupos. Os resultados sugerem que os fãs de rock clássico participantes desses grupos compartilham um senso de comunidade como forma de enfrentamento à ideia de individualismo e perda de propósito, de modo a criar, preservar e disseminar uma visão idealizada dos anos 1960 e 1970, representada como uma era autêntica.

Palavras-chave: Consumo Utópico. Autenticidade. Comunidades Virtuais. Rock Clássico.

\section{AUTHENTICITY AND CLASSIC ROCK CONSUMPTION: A NETNOGRAPHY ON FACEBOOK}

\footnotetext{
ABSTRACT

${ }^{1}$ Recebido em 28/12/2015, aprovado em 18/09/2017.

${ }^{2}$ Universidade Federal Rural do Rio de Janeiro (Brasil) - fmh.faetec@gmail.com

${ }^{3}$ Universidade Federal Rural do Rio de Janeiro (Brasil) - bill.pereira4@gmail.com
} 
In contemporary society, several movements have or had in music consumption one of the main ways to express their values, ideologies, and discontents. In this regard, rock music is noteworthy because even its origin was considered as a form of social protest. The objective of this study was to investigate how classic rock fans build and express meanings of authenticity through participation in Facebook groups on classic. For that purpose, a 12 months netnography was conducted in two Facebook groups on classic rock. Plus, 11 indepth interviews were conducted with users of these groups. The results suggest that classic rock fans of these groups share a sense of community as a way of dealing with the idea of individualism and loss of purpose creating preserving and disseminating an idealized vision of the 1960s and 1970s, represented as an authentic era.

Keywords: Utopian Consumption. Authenticity. Virtual Communities. Classic Rock.

\section{AUTENTICIDAD Y CONSUMO DEL ROCK CLÁSICO: UNA NETNOGRAFÍA EN FACEBOOK}

\section{RESUMEN}

En la sociedad contemporánea, varios movimientos tienen o han tenido en el consumo de la música una de las principales maneras de expresar sus valores, ideologías y descontentos. En especial, con relación a la música rock hay que destacar que en su origen fue considerada una manera de protesta social. El objetivo de este estudio fue investigar cómo los fans del rock clásico construyen y expresan significados de autenticidad mediante la participación en grupos de Facebook en la red. Para ello, se realizó una netnografia en dos grupos de Facebook en el rock clásico durante 12 meses, más 11 entrevistas en profundidad con los usuarios de estos grupos. Los resultados sugieren que los participantes aficionados al rock clásico comparten un sentido de comunidad como una forma de hacer frente a la idea del individualismo y la pérdida de propósito, de crear, preservar y difundir una visión idealizada de los años 1960 y 1970, representados como la era auténtica.

Palabras-clave: Consumo Utópico. Autenticidad. Comunidades Virtuales. Rock Clásico. 


\section{INTRODUÇÃO}

$\mathrm{Na}$ sociedade contemporânea, vários movimentos - como os hippies e os punks, por exemplo - têm ou tiveram no consumo de música uma das principais formas de expressar seus valores, ideologias e descontentamentos, sendo que o rock merece destaque em vários desses movimentos, pois sua própria origem incluiu formas de contestação social (CHACON, 1982).

O rock surgiu na década de 1950 nos EUA, reunindo elementos dos gêneros pop music, rhythm and blues e country and western music, massificando-se no final da década de 1960 e início dos anos 1970 (CHACON, 1982). Contudo, ainda hoje é possível verificar a presença de consumidores, inclusive jovens, de produtos, serviços e experiências associadas ao rock daquele período.

Com a popularização da internet e das redes sociais online, tornou-se possível para os fãs de rock encontrar e compartilhar informações sobre músicas, bandas e shows que já não fazem parte do mainstream da indústria fonográfica, como, por exemplo, as bandas consideradas de rock clássico que fizeram sucesso principalmente nos anos 1960 e 1970. Como o consumo de música envolve identificação e investimento afetivo do indivíduo (YAZICIOGLU, 2010; DIAS e RONSINI, 2008), adotou-se neste trabalho a conceituação de "fã" utilizada por Kozinets (2001, p. 69). Segundo o autor, o fã é caracterizado pela identificação e pelo investimento afetivo em relação a objetos ou imagens criados pela mídia de massa.

O compartilhamento de músicas digitais pode criar no consumidor um senso de pertencimento a uma comunidade imaginada (BELK, 2013). Além disso, o crescimento das redes sociais online permite não somente o compartilhamento de informações e experiências de consumo, mas também a formação de comunidades virtuais online em torno de marcas, produtos, séries de televisão e estilos musicais (KOZINETS, 2010; MUNIZ e O'GUINN, 2001). Em outras palavras, as comunidades virtuais permitem aos consumidores ressignificar objetos do passado, de modo a atribuir significados diferentes daqueles construídos pelo mercado (HIGSON, 2014). Nesse sentido, a ressignificação do passado seria uma forma do consumidor atribuir autenticidade a esses objetos (RIBEIRO, 2005; CAMPBELL, 2001).

A divisão simbólica entre o autêntico e o inautêntico é construída culturalmente e não necessariamente uma propriedade inerente dos objetos (THOMPSON, RINDFLEISCH e ARSEL, 2006). Marcas, celebridades, músicas e outros elementos materiais ou simbólicos também recebem classificações referentes à sua autenticidade. Esta busca da autenticidade, de 
acordo com Barbosa e Campbell (2008), seria uma característica do consumidor contemporâneo no sentido de que a fragmentação das identidades em meio às diversas e mutantes formas de identificação cria no um dilema: se por um lado ele é 'livre' para construir diversas identidades, por outro vive uma ansiedade ao questionar-se sobre seu verdadeiro self. A busca de significados de autenticidade por meio do consumo seria uma forma do consumidor vislumbrar algo essencial e duradouro em meio à 'liquidez' da contemporaneidade (BAUMAN, 2008).

Uma das formas de busca do autêntico relaciona-se à recriação do passado no presente, de modo a desvincular os objetos dos seus contextos originais e dos significados atribuídos pelo mercado (RIBEIRO, 2005; MACLARAN e BROWN, 2005; BEVERLAND e FARELLY, 2010). Bandas de rock como The Beatles e Pink Floyd, por exemplo, surgiram e terminaram nas décadas de 1960 e 1970 e ainda hoje são apreciadas, inclusive por jovens que não vivenciaram aquele período, sendo rotuladas pelos consumidores de rock como bandas 'clássicas'.

Assim, o objetivo deste trabalho foi investigar como fãs de rock clássico constroem e expressam significados de autenticidade por meio da participação em grupos do Facebook sobre rock clássico. O consumo de música é tomado como objeto de pesquisa para investigar a construção de significados de autenticidade na sociedade contemporânea. Como o rock clássico é um estilo musical que envolve significados e produtos relacionados ao passado (principalmente às décadas de 1960 e 1970) que continuam sendo consumidos nos dias atuais, escolheu-se este contexto para entender como os fãs de rock criam delimitações simbólicas entre o autêntico e o inautêntico. Acredita-se que os princípios e categorias culturais utilizados por estes fãs podem orientar a construção de ideais de autenticidade por outros grupos cujo consumo orienta-se para tempos e lugares idealizados.

\section{REFERENCIAL TEÓRICO}

\subsection{CONSUMO E UTOPIA}

De acordo com Campbell (2001), uma revolução cultural teve origem com o nascimento de uma ética romântica em meio à burguesia europeia no século XVIII, contexto em que florescia concomitantemente a ética protestante weberiana. $\mathrm{O}$ autor sustenta que a obra de Weber explica somente uma parte da ascensão do capitalismo, pois sua teoria 
descreve o surgimento de um espírito que legitima a racionalidade e o trabalho como conceitos centrais na sociedade, mas negligencia o papel consumo.

A ética romântica teria como impulso o nascimento de um público leitor de ficção, a expansão das horas vagas e a ascensão do amor romântico e da moda (CAMPBELL, 2001). No campo religioso, uma maior aceitação das emoções legitimara moralmente o sentimentalismo. Tais fenômenos constituiriam a base para o nascimento do hedonismo auto ilusivo, que de acordo com o autor caracteriza o consumo contemporâneo. Esse tipo de hedonismo caracteriza-se pela criação de ilusões como fonte de obtenção de prazer. A idealização de significados de perfeição relacionados a um bem proporcionaria ao indivíduo mais prazer do que a aquisição deste, pois a correspondência entre imaginação e realidade levaria o consumidor ao desencantamento desse produto.

Dessa forma, a idealização romântica teria como característica a criação hedônica de ilusões, no sentido de que a própria idealização proporcionaria prazer ao consumidor. A busca do prazer criado imaginativamente se expressaria por meio da cobiça de um bem, ou seja, cobiçar um bem seria mais prazeroso do que propriamente adquiri-lo. Segundo McCraken (2003), a aquisição desse bem pode representar uma forma de desencantamento, já que a experiência empírica submeteria os significados idealizados à imperfeição.

Este espírito romântico de idealização, segundo Ribeiro (2005), explicaria, por exemplo, o comportamento dos colecionadores de objetos do passado, pois o colecionismo envolve a ressignificação do passado de modo a criar um senso de autenticidade. Essa ressignificação seria uma forma hedonista de idealização de um tempo melhor do que o presente em um passado imaginado como autêntico. Os objetos, pontes entre o mundo real e o mundo ideal (MCCRAKEN, 2003), serviriam como uma forma de experimentação utópica deste passado, na medida em que o ressignifica no presente sem que possa ser efetivamente experimentado (HIGSON, 2014).

Essa busca por autenticidade seria um fenômeno contemporâneo, pois grande parte das referências culturais que servem como recursos simbólicos para construção de identidades pelo consumidor são percebidos como inautênticas (BELK, 1990; GOULDING, 2000; MCCANNEL, 1973). Essa percepção leva os indivíduos a buscar significados de autenticidade em outras dimensões espaço-temporais, de modo a deslocar os significados de autenticidade para lugares e épocas idealizadas que não foram vivenciados (KOZINETS, 2001; HIGSON, 2014). Ou seja, o consumo utópico seria caracterizado pelo deslocamento de significados pelo consumidor para dimensões do tempo e espaço não vivenciados. $\mathrm{O}$ consumo seria, então, a forma utilizada pelo indivíduo para entrar em contato com 
significados de autenticidade idealizados (MCCRAKEN, 2003; CAMPBELL, 2001; GOULDING, 2000).

Essa busca da autenticidade possui um caráter utópico na medida em que a utopia constitui um espaço de neutralidade no qual contradições são permitidas (MACLARAN e BROWN, 2005). Essas contradições dizem respeito, por exemplo, à busca pelo passado não como algo concreto que existiu, mas por um passado criado pela imaginação. MacLaran e Brown (2005), por exemplo, encontraram que as mudanças ocorridas no Powerscourt Town Center, na Irlanda, desencadearam um sentimento de nostalgia entre os consumidores que frequentavam o local, de modo que estes passaram a narrar a versão antiga do local como perfeita. Em outras palavras, o antigo centro comercial passou a existir somente na memória coletiva dos consumidores, memória esta criada como uma utopia de um tempo e de um lugar melhor. Conforme destacam os autores, os consumidores parecem ter reconstruído utopicamente o passado de modo a associá-lo a significados de perfeição, mesmo que esse passado não tenha sido efetivamente perfeito.

Para Goulding (2000), uma contradição característica do consumo utópico é a busca pelo consumidor de uma experiência autêntica no passado, ao mesmo tempo em que reconhece a natureza inalcançável dessa autenticidade. Assim, o passado utópico não trata de um passado que "existiu" concretamente para o indivíduo, mas de uma realidade criada a partir da ressignificação de determinados elementos do passado, de modo a sacralizá-lo (BELK, WALLENDORF e SHERRY, 1989). O estudo de Ribeiro (2005) demonstrou que os colecionadores reinterpretam os significados dos objetos colecionados sob perspectivas diferentes daquelas em funções das quais estes foram produzidos, de modo a atribuir-lhes significados de autenticidade.

Dessa forma, o consumo de produtos e experiências associados a outras dimensões de espaço e tempo parecem constituir formas pelas quais o consumidor contemporâneo busca a autenticidade, mesmo que reconheça a impossibilidade de alcançá-la.

\subsection{CONSUMO E AUTENTICIDADE}

A divisão simbólica entre o autêntico e o inautêntico é construída culturalmente e não necessariamente uma propriedade inerente dos objetos (THOMPSON et al., 2006). Marcas, celebridades, músicas e outros elementos materiais ou simbólicos também recebem classificações referentes à sua autenticidade. As primeiras discussões sobre autenticidade parecem ter se inspirado na obra de MacCannel (1973), desenvolvida no âmbito 
do turismo, que afirma que o mundo contemporâneo é percebido como artificial e inautêntico, de modo que o consumidor busca experiências autênticas por meio da visita a lugares que permitam ver a vida como ela "realmente é vivida".

No âmbito do marketing, o estudo de Leigh, Peters e Shelton (2006) relata como os consumidores da subcultura de consumo do MG (automóvel britânico) desempenharam o papel de co-criadores da autenticidade da marca. Holt (2002) também trabalhou a autenticidade associada ao branding e argumenta que as marcas são consideradas autênticas quando percebidas como originais, além de constituírem uma fonte de recursos culturais para o indivíduo construir seu self do modo que desejar.

Goulding (2000) investigou a percepção dos significados de autenticidade por visitantes de museus e identificou três grupos de consumidores com visões distintas. O primeiro grupo é formado por pessoas que vêem o presente como alienante e procuram experiências autênticas que lhes permitam escapar desse presente. $\mathrm{O}$ segundo, idealiza eras passadas autênticas através de percepções do passado relacionadas às artes, arquitetura e artesanato. Já o terceiro grupo é composto por indivíduos que buscam lazer e educação, não têm problemas com o presente e não apresentam evidência de idealização do passado, buscando autenticidade nos objetos em si, ou seja, avaliam os objetos como 1'verdadeiros' ou 'falsos' com base em suas propriedades constitutivas.

Adicionalmente, Wang (1999) elenca três tipos de autenticidade: objetiva, construtivista e existencial. A autenticidade objetiva faz referência à percepção de originalidade dos objetos pelo consumidor, podendo ser constatada por meio da análise objetiva de suas propriedades. A construtivista concebe a autenticidade como um construto social que envolve pontos de vista, crenças e perspectivas relativas, sendo negociável, ideológica e determinada pelo contexto. A existencial não leva em consideração as características do objeto/lugar em si, mas os sentimentos pessoais ativados pelo engajamento em atividades não ordinárias que libertam o indivíduo das restrições do dia-a-dia.

Grayson e Martinec (2004) desenvolveram os conceitos de autenticidade indexada e autenticidade icônica em relação às ofertas de marketing. A autenticidade indexada seria aquela que faz referência ao original e está relacionada à percepção de que determinado objeto não é uma cópia ou imitação. A autenticidade icônica está relacionada à ideia de 'reprodução autêntica' do original, no sentido de que um ícone seria percebido como algo que resgata as propriedades do original por meio da similaridade.

Neste sentido, Beverland e Farrely (2010) argumentam que a autenticação de um objeto está relacionada aos objetivos do consumidor. Estes objetivos podem ser divididos em 
três grupos. No primeiro, o consumidor buscaria a autenticidade para 'sentir-se no controle', isto é, buscaria objetos que lhe permitem expressar sua soberania pessoal em relação às escolhas de consumo. No segundo, o consumidor buscaria objetos e experiências que o conectem a um 'outro relevante' para 'sentir-se conectado'. Por fim, no terceiro, o consumidor perceberia como autênticos os bens que lhe permitem 'sentir-se virtuoso', ou seja, colocar em prática valores morais desejados.

Borschke (2014) relata como a incorporação da ideologia folk pelo rock criou um discurso de identidade coletiva autêntica. No âmbito da música, segundo Frith (1981 apud BORSCHKE, 2014) o termo folk relaciona-se à ideia de representação de uma experiência comunal, ao mesmo tempo em que valoriza a expressão individual como um tipo de experiência verdadeira do self. Segundo a autora, ao aderir à ideologia folk, o rock conseguiu separar o trabalho artístico da sua forma de commodity (produto fonográfico); conseguiu elevar o artista ao enfatizar a sua expressão individual, seu instinto, comunicação direta e emoções contra um mundo que é comercial, racional e mecanizado. A autora ainda destaca que a própria noção de autenticidade é romântica na medida em que busca uma verdade, uma essência.

Lewin e Willians (2009), em seu estudo sobre a noção da autenticidade na subcultura punk, sugerem que a autenticidade pode significar um ideal moral romântico, ou seja, valoriza a criatividade, a reflexividade, a originalidade, o autodescobrimento e a rejeição do status quo. Esse ideal moral, de acordo com Taylor (2011), seria regido por uma ética da autenticidade, na qual o indivíduo se sentiria pleno ao confrontar as convenções sociais desenvolvidas para o self.

O surgimento desta ética da autenticidade, segundo Taylor (2011), funda-se em três mal-estares da sociedade contemporânea. O primeiro deles é o individualismo. Para o autor, o indivíduo antes era fixado em determinados lugares, papéis e estratos dos quais era praticamente impensável se desviar. Essas referências, porém, ao mesmo tempo em que limitavam as pessoas, davam sentido ao mundo, de modo a criar um senso de conexão. $\mathrm{O}$ segundo mal-estar é o desencantamento do mundo. Para o autor, a perda do senso de conexão condicionada pelo individualismo quebrou o encanto dos significados do mundo, de modo que a ideia da existência de um 'propósito maior' foi substituída pela primazia da razão instrumental, que seria o "tipo de racionalidade em que nos baseamos ao calcular a aplicação mais econômica dos meios para determinados fins (TAYLOR, 2011, p. 14)”. O terceiro malestar seria a percepção de que as estruturas e instituições da sociedade restringem as escolhas do indivíduo. Esses três mal-estares levariam ao medo da perda de horizontes morais, dos 
propósitos e da liberdade. Dessa forma, o ideal de autenticidade seria o ideal moral predominante na contemporaneidade.

Das diversas perspectivas sobre autenticidade apresentadas, verifica-se que ela pode significar desde a comprovação da originalidade de um bem por meio de suas propriedades essenciais até um ideal moral contemporâneo. Este trabalho investigou a autenticidade sob esta segunda perspectiva, pois seu foco não leva em consideração as avaliações do consumidor sobre a originalidade do produto fonográfico em si, mas o modo como os sujeitos investigados utilizam a noção de autenticidade para delimitar barreiras simbólicas entre os valores e práticas de consumo que consideram autênticos.

Uma forma pela qual o consumidor persegue o ideal de autenticidade é por meio da conexão com indivíduos que compartilham valores, rituais e tradições para criar um propósito maior no qual as normas de socialização possuem significados que não são percebidos como baseados na razão instrumental. Essa forma de conexão seria o compartilhamento de um senso de comunidade. Nos dias atuais, a internet permite às pessoas que compartilham um senso de comunidade unirem-se também no ambiente virtual.

\subsection{Comunidades virtuais}

A popularização da internet permitiu o surgimento de novas formas de interação dos consumidores entre si e entre estes e as organizações no ambiente online, criando condições para a emergência das comunidades virtuais. Para Levy (1999), as mudanças tecnológicas, culturais e sociais impulsionadas pela emergência do ciberespaço teriam criado um novo conjunto de práticas, atitudes, modos de pensamentos e valores: a cibercultura. Kozinets (1998) conceitua cibercultura como o compartilhamento de comportamentos padronizados, bem como de seus significados simbólicos associados, principalmente por meio da comunicação mediada por computador. Assim, a cibercultura seria proveniente da interação do sujeito com o ciberespaço, refletindo as ações humanas no ambiente virtual. Nesse sentido, a criação de comunidades virtuais seria uma prática oriunda desse novo cenário cultural, no sentido de que esta reflete no ambiente virtual a ação humana de agregação em torno de interesses comuns, orientando-se por normas, valores e atitudes específicos.

O conceito de comunidade, para Muniz e O'Guinn (2001), teve origem no final do século XIX e representa uma crítica social à modernidade. A ideia central do conceito de comunidade era a de que algo natural e real (a comunidade) estava sendo substituído por algo 
despersonalizado e massificado (a sociedade moderna). De acordo com Muniz e O'Guinn (2001, p. 413), uma comunidade possui pelo menos três elementos:

a) Conexão entre indivíduos - é a ligação que os membros sentem em relação uns aos outros e o senso coletivo de diferença em relação àqueles que não pertencem à comunidade. O estudo etnográfico de Pereira e Ayrosa (2012), por exemplo, ilustra o sentimento de conexão entre consumidores gays cariocas, de modo que estes delimitam uma fronteira simbólica entre o 'mundo gay' e o 'mundo hétero' - aqueles que não pertencem à comunidade.

b) Rituais e tradições compartilhados - servem para perpetuar as histórias, cultura e consciência coletiva da comunidade. Schouten e McAlexander (1995), por exemplo, descobriram que os consumidores da marca Harley-Davidson compartilham rituais e tradições que sacralizam a marca.

c) Senso de responsabilidade moral - os membros da comunidade possuem um senso de dever para com a comunidade como um todo, bem como para seus membros. Lewin e Vannini (2009) sugerem que os punks possuem um senso de compromisso com a comunidade, de modo a colocar em prática seus valores morais dentro e fora do grupo.

Com o advento das modernas tecnologias comunicacionais, do marketing contemporâneo e da mídia de massa, a noção de comunidade foi ampliada ao reunir indivíduos dispersos geograficamente em torno de um interesse. Em outras palavras, a comunidade deixou de ser associada a uma ideia de lugar, passando a ser desterritorializada e a representar uma identidade compartilhada (MUNIZ e O'GUINN, 2001; LEVY, 1999). Um exemplo é o trabalho de Scaraboto e Fisher (2013), que analisaram como os consumidores considerados 'gordos' segundo os padrões da indústria da moda compartilham valores e uma identidade coletiva em algumas comunidades virtuais para reivindicar maior inclusão no mercado consumidor de moda.

\section{METODOLOGIA}

O objetivo deste trabalho foi compreender a construção e expressão de significados de autenticidade por meio do consumo de rock clássico em grupos do Facebook pelo ponto de vista dos sujeitos estudados, alinhando-se à epistemologia interpretativista, na

qual não se pretende realizar generalizações a respeito dos significados estudados (MORGAN, 2007). O foco foi a compreensão de como este grupo particular de consumidores cria e expressa significados por meio do consumo. Além disso, entende-se que as próprias 
experiências subjetivas e intersubjetivas do pesquisador decorrentes do trabalho de campo criam interpretações - e não 'verdades' - sobre o contexto de consumo estudado (BELK, FISHER e KOZINETS, 2013).

A coleta de dados foi realizada por meio de uma netnografia de 12 meses em dois grupos do Facebook sobre rock clássico. A netnografia envolve a adaptação da metodologia tradicional da etnografia ao estudo de culturas e comunidades online formadas por meio da comunicação mediada por computadores, especificamente no âmbito dos estudos do consumo em marketing (KOZINETS, 2006a). Adicionalmente, foram realizadas 11 entrevistas em profundidade com duração média de 60 minutos junto a membros dos grupos analisados. As entrevistas foram conduzidas por meio da ferramenta Skype da Microsoft, gravadas, transcritas e analisadas juntamente com os dados coletados por meio da netnografia. Quanto ao número de entrevistas, seguiu-se a recomendação de Belk et al. (2013), de que a quantidade depende da saturação do assunto, ou seja, o ponto em que não se obtêm novos insights relevantes sobre a questão investigada, o que aconteceu por volta da nona entrevista.

Segundo Kozinets (2010), o primeiro passo para a realização de uma netnografia é o planejamento da entrada na cibercultura ou comunidade virtual que se deseja estudar. Os critérios sugeridos por Kozinets $(2002 ; 2006 \mathrm{~b})$ para a escolha das comunidades virtuais mais adequadas ao estudo são os seguintes: (1) as comunidades devem estar relacionas à pergunta de pesquisa; (2) devem possuir bom tráfego de mensagens postadas por diferentes membros; (3) devem fornecer dados ricos, ou seja, mais detalhados e descritivos; e (4) devem apresentar grande interação social.

Seguindo as recomendações anteriormente citadas, foram selecionados, inicialmente, quatro grupos do Facebook: "Parayso dos Loucos: Rock 60 e 70", "Lendas do Rock", "Clássicos do rock" e "Clássicos do Rock e do Heavy Metal". A escolha se deu com base nos seguintes critérios: (a) os grupos deveriam expressar em seus títulos ou descrições as palavras "rock clássico", "classic rock", "rock 60", "rock 70", "rock antigo"; (b) deveria haver mais de 10 interações diárias entre seus membros, de modo que estes apresentassem opiniões e discutissem sobre rock; e (c) o grupo deveria ser composto por, no mínimo, 3000 membros.

Após a seleção dos grupos, o pesquisador pediu autorização aos administradores para realizar a pesquisa. Os administradores do grupo "Clássicos do Rock" e do grupo “Clássicos do Rock e do Heavy Metal” não concordaram. Por questões éticas, estes grupos foram abandonados. Assim, a netnografia foi realizada junto aos grupos "Lendas do Rock" e 
"Parayso dos Loucos: Rock 60 e 70", cujos administradores autorizaram expressamente a realização da pesquisa junto aos seus membros.

Após a escolha e a entrada em comunidades virtuais, Kozinets (2006 b) ressalta que o pesquisador deve coletar e analisar dados dessas comunidades, os quais podem ser classificados em três grupos: (1) dados copiados diretamente da comunidade pelo pesquisador (p. ex.: interações entre membros da comunidade em um fórum); (2) dados provenientes da observação da comunidade (p. ex.: diário de campo ou em notas de campo); e (3) dados originados em entrevistas com membros da comunidade pesquisada (p. ex.: transcrições de entrevistas). Como o pesquisador se tornou membro de cada um desses grupos, a coleta de dados foi feita por meio: (a) da cópia de textos e imagens dos grupos relevantes para a pesquisa; (b) da anotação de interações relevantes em notas de campo; e (c) da realização de entrevistas em profundidade com membros dos grupos observados por meio da ferramenta de comunicação instantânea Skype. Os dados textuais, imagens e interações relevantes foram coletados e observados durante 12 meses. A observação participante foi realizada, em média, 8 horas por semana, sendo que levava em consideração eventos que ocorriam no momento em que o pesquisador participava dos grupos, assim como eventos anteriores à observação, mas que ficavam gravados. As entrevistas em profundidade foram realizadas por Skype junto a 11 membros dos grupos estudados, gravadas, transcritas e analisadas. Cada entrevista durou cerca de 60 minutos.

A terceira recomendação para a realização de uma pesquisa netnográfica é a observação de questões éticas, no sentido de que o pesquisador deve ter cuidado especial para que nenhum dano decorrente do estudo seja causado à comunidade analisada. Seguindo esta recomendação, conforme destacado anteriormente, o pesquisador pediu autorização aos administradores dos grupos para a realização da netnografia. O pedido foi realizado por meio do envio de uma mensagem eletrônica e de conversa coletiva com estes para esclarecer o modo como a pesquisa seria realizada. Os administradores dos grupos "Lendas do Rock" e "Parayso dos Loucos: Rock 60 e 70" aceitaram dialogar com o pesquisador, esclareceram suas dúvidas sobre a pesquisa e permitiram a realização da netnografia. Os administradores dos grupos "Clássicos do Rock" e "Clássicos do Rock e do Heavy Metal” não se manifestaram contra ou a favor da realização da pesquisa, mas o pesquisador entendeu não ser ético prosseguir a netnografia nestes grupos sem o consentimento de seus administradores.

Por fim, o quarto procedimento da netnografia é o member check, que significa a apresentação de alguns ou de todos os resultados de uma investigação às pessoas que foram 
estudadas para que se obtenha seus comentários (KOZINETS 2002, 2006b). Nesse sentido, uma das administradoras do grupo "Lendas do Rock" auxiliou na entrada na cibercultura investigada e na análise dos dados por meio de conversas informais que forneceram insights valiosos a respeito da participação do pesquisador nos grupos e de categorias teóricas que emergiram durante a pesquisa.

A análise dos dados coletados por meio da netnografia e das entrevistas em profundidade foi realizada por meio da análise interpretativa, utilizando-se o processo hermenêutico (THOMPSON, 1997). Esta análise foi utilizada por Thompson (1997) para se compreender como consumidores constroem e ressignificam o mundo dos produtos onde vivem.

Na seção a seguir, se apresenta a interpretação dos dados coletados por meio das entrevistas em profundidade e da netnografia.

\section{ANÁLISE DOS DADOS}

As categorias apresentadas a seguir emergiram da análise interpretativa dos dados, fruto da análise das notas de campo e das entrevistas em profundidade feitas durante a pesquisa.

\subsection{SENSO DE COMUNIDADE}

A análise dos dados demonstrou a existência de um forte senso de comunidade entre os usuários. Utiliza-se a palavra "comunidade", e não "comunidades", pois os sujeitos analisados compartilham um mesmo senso de comunidade, mesmo residindo em regiões geograficamente distantes e participando de vários grupos do Facebook sobre rock, o que caracteriza a comunidade analisada como uma comunidade virtual no sentido de ser desterritorializada (LEVY, 1999).

Este senso de comunidade se expressa por quatro aspectos: conexão entre os membros da comunidade; construção de barreiras simbólicas para preservar os significados de autenticidade; hierarquia de status baseada no conhecimento e idade; e critérios de autenticação de membros. Este senso de comunidade parece ser utilizado pelos fãs de rock dos grupos do Facebook estudados para criar, preservar e buscar significados de autenticidade. 
3.1.1 Conexão entre os membros da comunidade

A conexão entre os indivíduos possui duas principais características: senso de ligação entre os indivíduos e senso de diferença coletiva em relação àqueles que não pertencem à comunidade (MUÑIZ e O'GUINN, 2001). O senso de diferença coletiva pode ser ilustrado pelo próprio nome de um dos grupos observados: "Parayso dos loucos: rock $60 \mathrm{e}$ 70". O recorrente uso do termo "louco" pelos informantes parece sugerir a existência de uma forte ênfase em ser diferente, no sentido de que esta diferença remeta à autenticidade. Segundo os informantes, o "louco" autêntico seria aquele que, ao assumir este rótulo, legitima sua pertença ante a comunidade, ao mesmo tempo em que reforça seu senso de diferença em relação aos indivíduos que estão fora desta (MUÑIZ e O'GUINN, 2001; TAYLOR, 2011; KOZINETS, 2001; PEREIRA e AYROSA, 2012).

Os sujeitos analisados parecem utilizar o sentido negativo da palavra "louco" sendo este sentido negativo atribuído, de acordo com a comunidade, pela "sociedade" - para se diferenciar e expressar sua autenticidade perante a comunidade de fãs de rock.

Para Jagger, por exemplo, os fãs de rock são vistos de uma forma negativa e estigmatizada pela sociedade:

Jagger - Talvez hoje algumas pessoas até tenham vergonha de admitir que gostam de rock...

Pesquisador - E por que haveria essa vergonha em admitir que se gosta de rock?

Jagger - Porque, basicamente, todo mundo acha que rockeiro é tudo louco, né...

Esta declaração condiz com os resultados de Kozinets (2001) sobre a comunidade de fãs da série Star Trek, que também utilizavam o estigma para fortalecer seus laços comunitários.

\subsubsection{Preservação dos significados}

A análise dos dados revelou que a comunidade busca resguardar os significados de autenticidade atribuídos aos produtos associados ao rock clássico por meio do estabelecimento de barreiras simbólicas (KOZINETS, 2001). A queixa reproduzida na Figura 1 ilustra a preocupação da comunidade com a ressignificação de produtos associados ao rock por outros consumidores. 
Figura 1 - Queixa de ameaça de ressignificação de produtos associados ao rock por não membros da comunidade

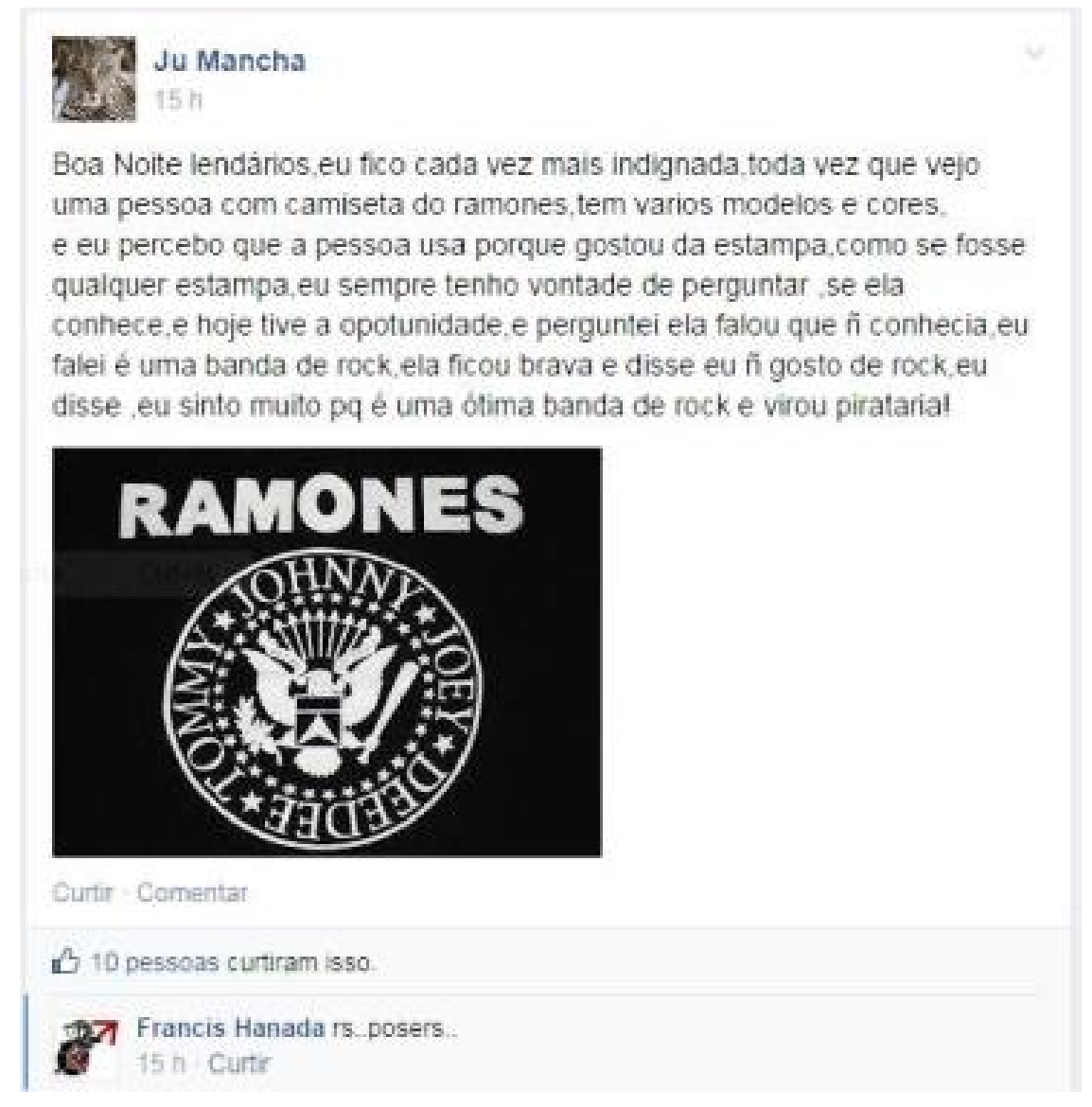

Fonte: Nota de campo, 15/09/2014.

Como ilustrado, para a comunidade analisada o mercado parece representar uma ameaça à autenticidade do rock clássico, pois os bens e experiências a ele associados seriam “contaminados" ao entrar em contato com novos mercados. Essa ressignificação seria, então, uma forma de tornar os produtos inautênticos, pois pessoas que não conhecem "os reais significados" dos produtos associados ao rock não poderiam consumi-los, segundo os fãs de rock (RIBEIRO, 2005).

Ainda na Figura 1, um sujeito classifica aqueles que não conhecem os significados dos produtos associados ao rock como posers. Segundo os informantes, poser seria o indivíduo que se veste e tenta agir como rockeiro para parecer um membro autêntico. O poser, apesar de ser relacionado à noção de inautenticidade, parece ser importante para legitimar o status dos "verdadeiros rockeiros" (SCHOUTEN e MCALEXANDER, 1995). Em outras palavras, os posers são aspirantes a membros da comunidade e seu esforço para serem 
legitimados parece reforçar o status e o comprometimento dos membros considerados autênticos.

\subsubsection{Hierarquia de status da comunidade}

A análise dos dados também revelou a existência de uma hierarquia de status no interior da comunidade baseada em dois aspectos: conhecimento sobre o rock e idade dos membros.

Com relação ao conhecimento sobre rock, os indivíduos que demonstram possuir maior conhecimento são os mais admirados pelos demais membros. Ser admirado nestes grupos significa receber convites para participar de outros grupos sobre rock no Facebook e criar amizades significativas com outros membros. O compartilhamento de conhecimento e de experiências de consumo sobre rock parece constituir o processo pelo qual os fãs de rock desenvolvem relacionamentos para se sentirem conectados (BEVERLAND e FARRELLY, 2010).

Vale ressaltar que os sujeitos são incluídos em grupos do Facebook geralmente por indicação de outros membros. Isso parece sugerir que quanto mais significativas forem as amizades desenvolvidas e quanto mais convites receber para participar de outros grupos, mais admirado é este individuo como autêntico fã de rock.

Eu percebo que recebo convite no meu face pessoal porque eu sempre posto coisa nova... Esses grupos pra mim só estão valendo porque eu estou conhecendo pessoas legais, porque do ponto de vista musical... Nada novo, cara. Ontem mesmo me incluíram em mais um grupo. Eu disse: "Minha filha, eu me sinto lisonjeado, mas o meu problema é tempo." Ela disse: "Não tem problema, porque você faz umas postagens legais... e vai atrair mais gente para o grupo” (Plant, 62 anos).

Para Plant, o fato de postar frequentemente músicas e assim expressar conhecimentos sobre rock serve para atrair novos membros para os grupos do Facebook sobre rock dos quais participa, bem como para desenvolver laços significativos com outros membros. Quando expressa sua insatisfação em relação à ausência de conteúdo novo nos grupos, parece querer, de fato, demonstrar que possui conhecimento sobre rock a ponto de não haver nos grupos nada que ele não conheça. Contudo, a análise das notas de campo mostra que Plant interage diariamente com outros membros nos diversos grupos dos quais 
participa, o que sugere que ele se considera um importante membro da comunidade devido ao seu amplo conhecimento e aos convites de amizade e de outros grupos que recebe.

O conhecimento superficial sobre rock, por outro lado, é visto de modo negativo pela comunidade.

Neste trecho, reproduzido na Figura 2, um sujeito classifica os fãs de rock que apenas conhecem as músicas "tocadas nas rádios" como "rockeiros pregos". O verdadeiro rockeiro seria aquele que conhece o máximo sobre a obra e a história de uma banda de rock. Logo, a comunidade parece perceber aqueles que conhecem rock de modo superficial como sendo inautênticos. Assim, um membro autêntico da comunidade analisada seria aquele que demonstra expertise e controle sobre a atividade de consumo em torno da qual a comunidade se constrói, neste caso, o rock clássico (LEIGH et al., 2006).

Figura 2 - Exemplo de interação onde aparece o termo "rockeiro prego"

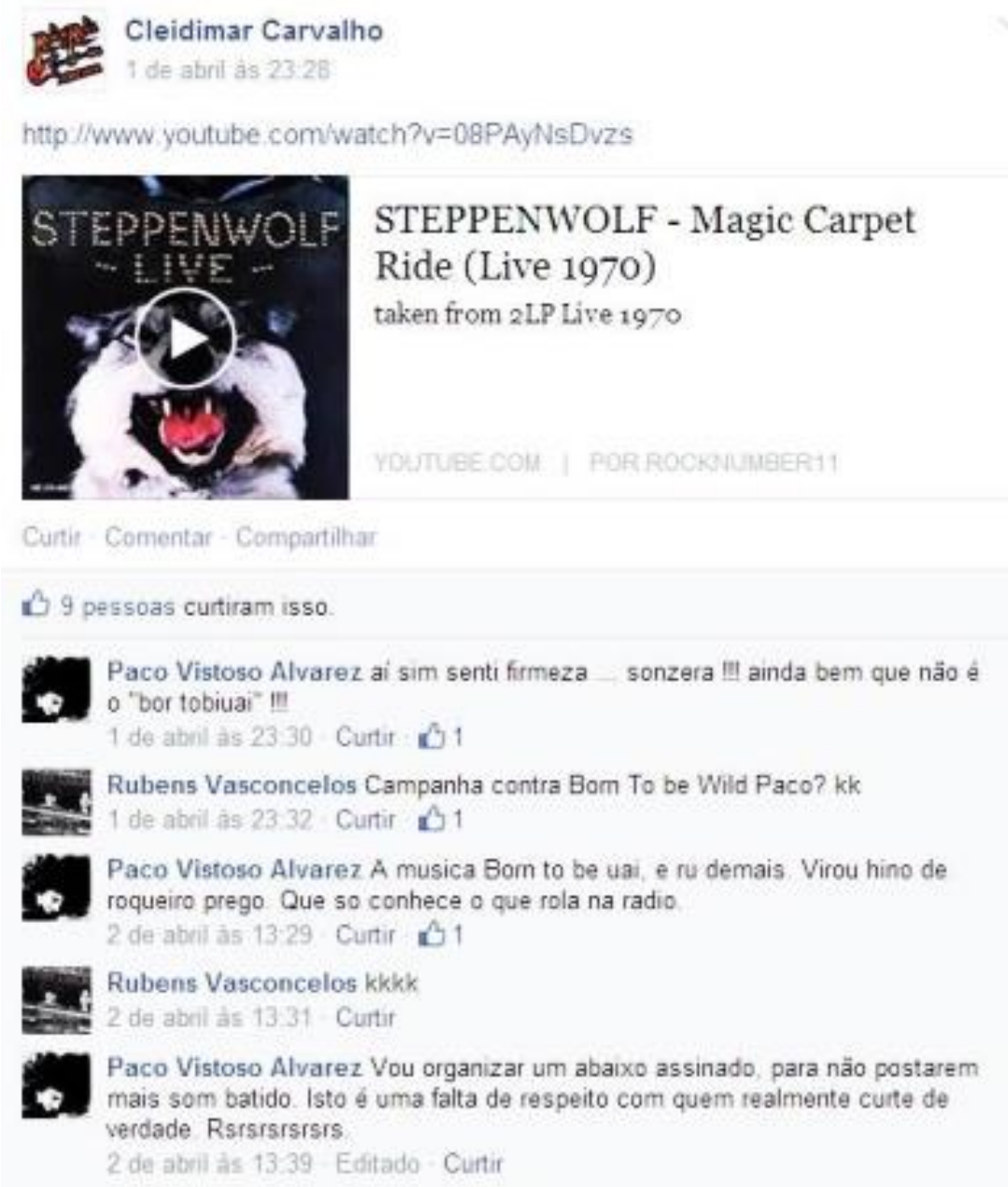

Fonte: nota de campo, 02/04/2014. 
Outra forma de hierarquização dos membros dos grupos analisados é a idade. A análise dos dados indica que para os sujeitos analisados, parece existir também uma associação entre idade e conhecimento. O relato a seguir, ilustra esta associação.

Um dia eu postei a música whiskey in the jar do Thin Lizzy, veio uma menina e disse: "Nossa, eu gosto mais da versão do Metallica... Esse pessoal adora fazer plágio”... Eu perguntei pra ela: “quantos anos você tem?" Ela disse: "Dezenove”. Eu falei: "então deixa quieto..." [tom de ironia e desprezo. (Davis, 32 anos).

Neste relato, Davis, ao perceber um equívoco relacionado ao rock de outro membro do grupo, rapidamente questiona sua idade. Sua reação de desprezo ao saber a idade da jovem parece indicar que Davis, apesar de relativamente jovem para um fã de rock dos anos 1960 e 1970 (pois nasceu na década de 1980), percebe os mais jovens como tendo pouco conhecimento sobre rock por não terem efetivamente vivenciado o período do surgimento e consolidação das bandas de rock clássico, ocupando, assim, uma posição inferior na hierarquia de status da comunidade.

O cara é vendedor de discos e chama o público que pode vir a comprar discos com ele de "modinha". Eu não sei o sentido de uma pessoa que vende disco agredir o público que compra com ele chamando o cara de "modinha". "Modinha” por quê? Só por que o cara nasceu em noventa? O cara não tem culpa de ter nascido em noventa, o cara pode ter nascido em noventa e sacar de Mutantes tanto quanto eu! (Hendrix, 44 anos).

Apesar de Hendrix afirmar não julgar fãs de rock pela sua idade, sua fala revela a existência de uma percepção na comunidade de que membros mais jovens são "rockeiros modinha" que, assim como o poser, tentam parecer rockeiro sem conhecer os "verdadeiros significados" dos produtos associados ao rock. Porém, a idade por si só não garante posições elevadas ou inferiores na hierarquia de status da comunidade. Tanto os jovens fãs de rock quanto os mais velhos devem provar sua autenticidade.

\subsubsection{Consumo e autenticação}

A análise dos dados sugere que o modo como os membros mais jovens e os mais velhos buscam comprovar seu conhecimento sobre rock perante a comunidade parece diferir: enquanto os fãs de rock mais jovens comprovam seu conhecimento principalmente pela 
postagem e compartilhamento de conteúdo informativo e pelo consumo de produtos que aumentem seu conhecimento sobre rock, os fãs mais velhos utilizam suas coleções como uma "comprovação física" de seu conhecimento e vivência do rock clássico. Um exemplo se encontra na Figura 3.

Figura 3 - Exemplo de criação e postagem de conteúdo por membro da comunidade

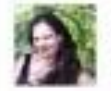

The Golliwogs Pre-Creedence Release $\bigcirc$ https / / www youtube comwatch? $y=$ Ocftwzjonuo

Música gravada em 1966, quando ainda se chamavam The Golitwogs, o embräo daquilo que viria a chamar-se um pouco mais tarde como Creedence Cleanwater Revival

A autoria desta música é assinada em dupla pelos imäos John Fogerty e Tom Fogerty, nesta tase John Fogerty começava a assumir a vocalizaçäo que ate ai estava a cargo de Tom Fogerty, tambem jà se notava que John Fogerty estava a assumir a liderança e dominio total da banda A música foi composta ao estilo de música Soul, com alguma semelhança ao estilo do cantor negro de música sout, Otis Redding facto curioso é que esta música era para ter entrado no primeiro album dos CCR mas depois resolveram deixa-la de fora e acabou por ficar esquecida nos corres da editora Fantasy Records que era a editora que representava esta banda Constituição da Banda John Fogerty. Tom Fogerty. Stu Cook. Doug Cliftord.

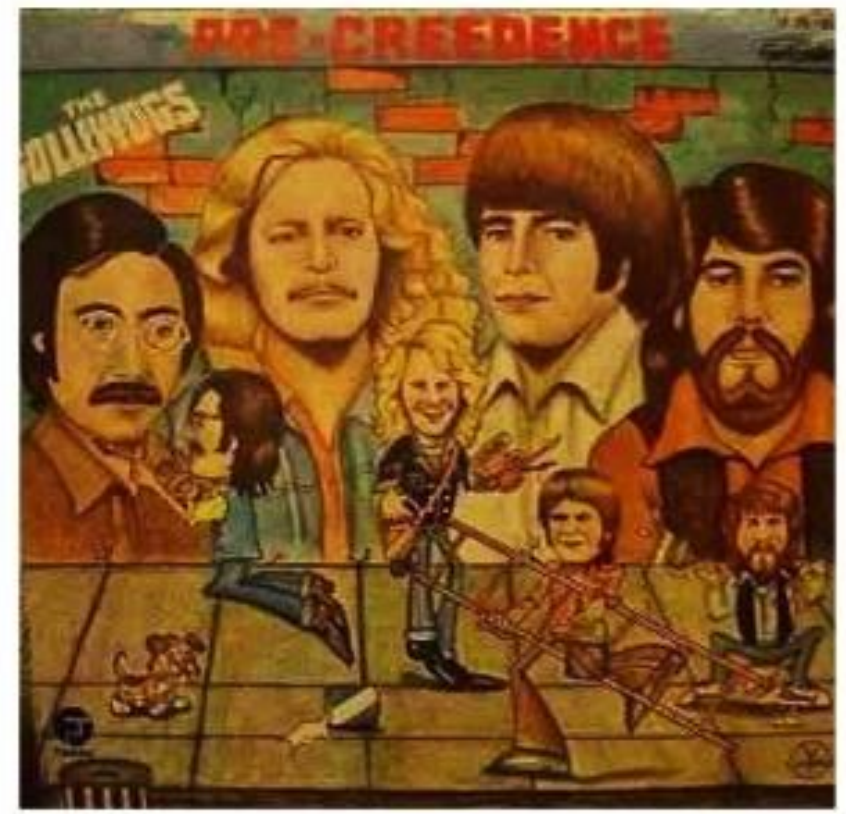

Curtif Comentar

Fonte: nota de campo, 25/04/2014. 
Como não vivenciou os anos 60 e 70, Davis parece sentir necessidade de comprovar para a comunidade que ele não somente gosta de rock, como também possui vasto conhecimento sobre o assunto.

Eu participo todos os dias [...]. Sempre você vai ver no "Lendas" uma postagem minha, tipo... Eric Clapton está fazendo aniversário, aí ele [o administrador] vai ali e coloca a foto. Eu vou e posto um artigo sobre ele... Busco quatro ou cinco fontes diferentes sobre o artista. Aí eu vejo o que bate, leio tudo, copio e colo num bloco de notas, pego as informações mais importantes, porque a informação conta muito para esses grupos (Davis, 32 anos).

Para expor esse conhecimento, Davis escreve quase diariamente textos sobre artistas e bandas de rock clássico. Comum entre os jovens, o compartilhamento de conteúdo sobre rock percebido como "original" parece ser uma das principais maneiras de um membro jovem buscar autenticação junto à comunidade.

Os bens também parecem desempenhar uma segunda função para os informantes: comprovar fisicamente o conhecimento e a relação do sujeito com o rock. Essa função parece estar associada ao processo de autenticação principalmente de fãs de rock mais velhos, ou seja, daqueles que vivenciaram as décadas de 1960 e/ou 1970.

Nessa época não tinha internet, então você ia ao sebo e corria atrás de literatura, revista dos anos setenta, dos anos oitenta... A "Som Três" era um bom guia dessa época e tinha umas edições especiais legais, tipo "Enciclopédia do Rock”, "Diário do Rock” ... Aliás, o "Diário do Rock" estou até com ele aqui [mostrando o produto na webcam] (Hendrix, 44 anos).

Ao falar de sua coleção, Hendrix não somente descreve os produtos que possui como também relata o modo como buscava e cuidava destes. Sua coleção de discos, revistas e livros sobre rock e as histórias pessoais a ela associadas parecem fornecer os elementos que comprovam sua autenticidade enquanto fã de rock. Isso condiz com a afirmação de Belk (1988), segundo a qual uma coleção representa uma forma de extensão da identidade do indivíduo no sentido de que os objetos colecionados e as histórias a eles associadas constituem uma forma de autodefinição do sujeito. A Figura 4, postada por um dos membros ilustra este ponto. 


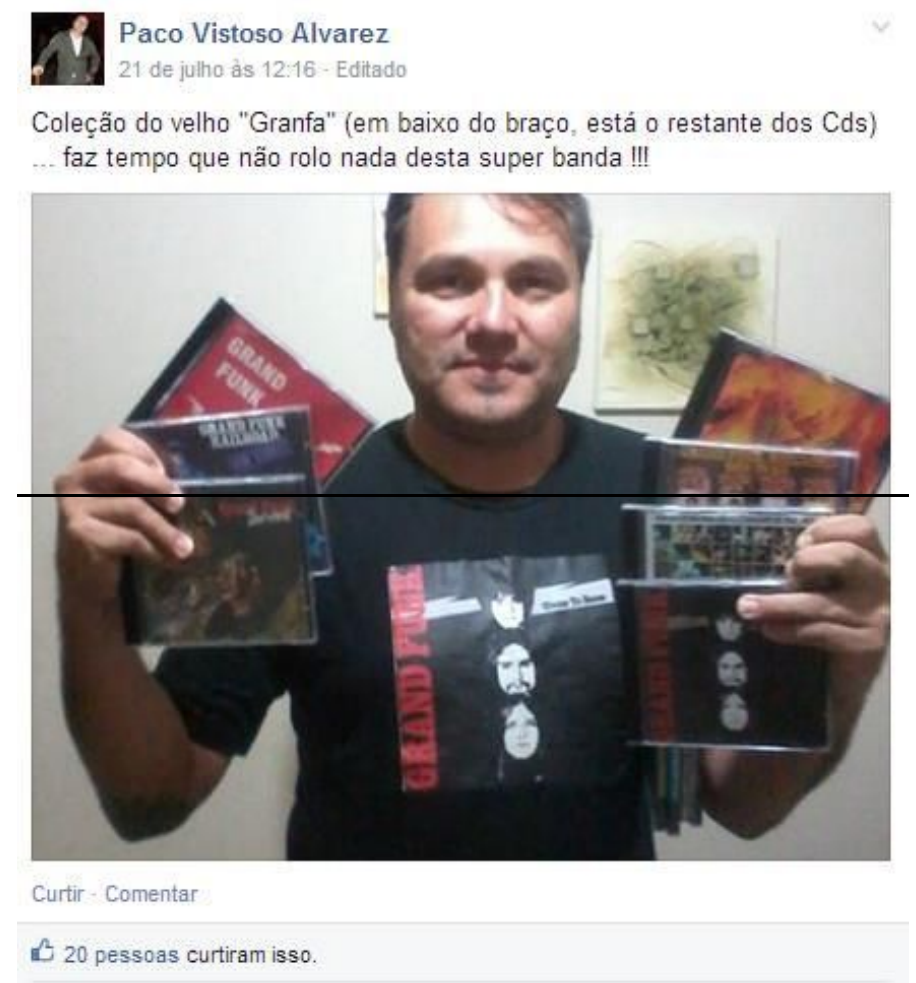

Fonte: nota de campo, 22/07/2014.

\subsection{AUTENTICIDADE}

Outra categoria que emergiu da análise dos dados foi a busca pelos sujeitos por um ideal de autenticidade presente no passado por meio do consumo utópico de músicas, objetos e experiências associadas ao rock clássico (GOULDING, 2000).

\subsubsection{O conceito de "clássico"}

Para a comunidade, o rótulo "rock clássico" não parece constituir um gênero musical, mas ser utilizado para distinguir as bandas de rock entre autênticas e inautênticas. Em outras palavras, a atribuição do rótulo "rock clássico" a uma banda constitui um processo coletivo de autenticação com base nos princípios culturais da comunidade.

O rock clássico pra mim é o rock que valoriza a música em si tentando aprimorá-la... E também com letras que tenham uma mensagem a transmitir. Hoje em dia o rock perdeu um pouco desse 
apelo por causa da mídia, que reverencia cantores e bandas que claramente não tem talento nenhum com o objetivo de ganhar dinheiro (Waters, 25 anos).

A citação anterior ilustra a percepção de que o artista ou banda de rock clássico trabalha em prol de um propósito "superior" ao lucro. Em outras palavras, o grupo percebe como autênticos as bandas e artistas que seguem ideais próprios, "únicos". O mercado, por outro lado, seria para os sujeitos analisados, uma fonte de padronização das pessoas e de destruição da autenticidade (MACCANNEL, 1973; GOULDING, 2001).

O Rush, uma de minhas bandas prediletas, usou sintetizadores, cabelos estilo mulet, blazers coloridos e visual New Age nos anos 80. Até os gigantes foram influenciados! Os mestres são únicos [...]. Podemos ter referências, mas clones são uma ofensa! Bandas especiais existem justamente por serem únicas (Harrison, 28 anos).

$\mathrm{O}$ relato de Harrison reforça a importância que a comunidade atribui à originalidade e genuinidade na busca de um propósito superior ao lucro. Sua fala parece alinhar-se com a visão de que a contemporaneidade é essencialmente inautêntica no sentido de que a perda do senso de propósito ante o domínio da razão instrumental teria levado a um constante questionamento sobre o que é autêntico (GOULDING, 2001; LEWIN e WILLIANS, 2009).

\subsubsection{Consumo utópico: a idealização de um passado autêntico}

Conhecer sobre rock clássico é uma forma dos sujeitos analisados expressarem sua autenticidade perante a comunidade. Essa demonstração de conhecimento envolve narrativas detalhadas sobre shows, discos, eventos, festivais, biografias e outros produtos. A análise dos dados revelou um aspecto peculiar relacionado ao jovem fã de rock: a visão de que os anos 60 e 70 eram melhores do que os dias atuais. Tome-se como exemplo o diálogo com Jagger:

Jagger - Eu acho que quem viveu na década de 60 e 70... Acho que com certeza deve ter sido bem mais feliz do que hoje [risos]. Porque teve todo esse negócio do "paz e amor"... A década de 70, que foi a época áurea, teve tanta coisa legal que surgiu, né... Hoje você vê aí pessoas mais conectadas com a internet, iphones, tablets... Antigamente, ninguém se preocupava muito com isso. 
Pesquisador - Como você vê esta época?

Jagger - A gente vê filmes, seriados que mostram um pouco como era a época. Nossa! Eles usavam calças boca-de-sino, camisas coloridas, cabelos grandões. Eu acho bacana. Realmente foi uma época linda pra quem viveu nela.

A não vivência dos anos 1960 e 1970 permite idealizar esse período como uma época "perfeita", onde as pessoas eram mais felizes e interagiam de modo mais autêntico. Como não se trata de uma representação de um tempo vivenciado, mas de uma reconstrução do passado no presente, ele é capaz de construir uma imagem idealizada e romântica desse período, que vai ao encontro do trabalho de Higson (2014) sobre o consumo nostálgico nas comunidades virtuais. Esse ponto é recorrente entre os jovens fãs de rock e corrobora a visão de Campbell (2001), para quem o consumidor contemporâneo "sonha acordado" de modo a se "autoiludir" e buscar nos produtos a correspondência entre imaginação e realidade. Sendo assim, os bens, músicas e experiências associadas ao rock parecem representar uma ponte entre os jovens fãs de rock e o passado utópico idealizado como autêntico. Esta idealização do passado pelos jovens fãs de rock talvez possa explicar também porque os membros mais velhos ocupam uma posição superior na hierarquia de status do grupo: estes parecem ser percebidos pelos jovens como autênticos representantes deste "passado idealizado", pois teriam vivenciado a "época áurea" do rock.

\section{CONSIDERAÇÕES FINAIS}

O objetivo deste trabalho foi investigar como fãs de rock clássico constroem e expressam significados de autenticidade por meio da participação em grupos do Facebook sobre rock. Os resultados sugerem que os fãs de rock compartilham uma percepção de que o mundo contemporâneo é dominado pela razão instrumental, sendo o compartilhamento de um senso de comunidade o modo pelo qual os fãs de rock dos grupos do Facebook analisados constroem significados de autenticidade para enfrentar esta dominação.

O senso de comunidade compartilhado pelos membros dos grupos virtuais estudados se expressa por quatro aspectos principais: sentimento de conexão entre os membros da comunidade; construção de barreiras simbólicas; hierarquia de status baseada no conhecimento sobre rock e idade do membro; e estabelecimento de critérios de autenticação de membros. Este senso de comunidade parece ser utilizado pelos fãs de rock do Facebook 
para criar, preservar e buscar significados de autenticidade por meio do consumo de rock clássico.

A comunidade analisada parece utilizar um discurso contra o mercado para isolar a ameaça ressignificação dos produtos por ela consumidos. Se um produto percebido por seus membros como sendo associado ao rock é apropriado pelo mercado e por outros grupos de consumidores, este produto deixa de ser autêntico. Nesse sentido, um produto autêntico seria aquele utilizado exclusivamente por indivíduos percebidos como autênticos rockeiros. A comunidade julga a autenticidade de um sujeito com base em seu conhecimento e envolvimento com o rock, expresso através do consumo de bens, músicas e experiências associados ao rock clássico e da participação do indivíduo nos grupos do Facebook sobre rock.

Outro importante achado deste trabalho refere-se à hierarquia de status da comunidade analisada, a qual se baseia nos critérios de conhecimento do indivíduo sobre rock e na idade dos indivíduos. A recompensa para os níveis mais elevados desta hierarquia é a admiração, expressa pelo recebimento de convites para participar de outros grupos do Facebook sobre rock e no desenvolvimento de amizades significativas com usuários desses grupos.

Todos os membros dos grupos observados devem comprovar sua autenticidade perante a comunidade pela demonstração de conhecimento e envolvimento com o rock. Os fãs de rock mais velhos geralmente utilizam suas coleções de produtos como discos de vinil, CDs, DVDs, fitas cassetes, revistas e livros sobre rock para comprovar sua autenticidade. Os consumidores mais jovens engajam-se na pesquisa e produção de conteúdo original para o grupo, principalmente na forma de biografias e curiosidades sobre bandas e artistas. $\mathrm{O}$ consumo de bens que proporcionem aprendizagem sobre rock também é uma forma utilizada pelos jovens para buscarem legitimação como membro da comunidade.

O significado de "clássico" parece ser utilizado pelo grupo para delimitar uma barreira simbólica entre o autêntico e o inautêntico com relação ao consumo de músicas, bens e experiências associadas ao rock. O rótulo "rock clássico" parece estar associado a bandas e artistas percebidos como relacionados a um propósito "superior", ou seja, propósitos que superam interesses meramente comerciais. Assim, a definição de categorias e princípios que delimitam o autêntico e o inautêntico pela comunidade analisada parece estar enraizada em uma percepção de que o mundo contemporâneo é dominado pela razão instrumental e que a busca da autenticidade é uma tarefa importante. 
A busca da autenticidade pela comunidade online estudada parece se expressar através da sustentação de uma visão idealizada dos anos 60 e 70. Assim, os usuários mais jovens parecem absorver os discursos românticos sobre esta época narrados pelos fãs de rock clássico mais velhos e deslocam os significados de perfeição para este passado idealizado, resguardando-os da experiência empírica e do desencantamento destes. Nesse sentido, o consumo de rock seria uma ponte entre o jovem fã de rock e os ideais deslocados para o passado que nunca o leva ao seu destino final. Nesse sentido, o consumo de rock clássico pelos indivíduos mais jovens seria utópico na medida em que estes jovens idealizam um tempo passado não vivenciado por eles como sendo melhor do que os dias atuais, o que se expressa no consumo de produtos e músicas dessa época, percebidos como autênticos.

No campo dos estudos do consumo, acredita-se que este trabalho traga contribuições ao abordar um tipo de consumidor que incorpora e cultiva discursos favoráveis a "bons tempos" relacionados a um passado idealizado. Estudos sobre o consumo e nostalgia como o de Holbrook (1993) investigaram como consumidores constroem narrativas sobre objetos, pessoas e lugares que um dia fizeram parte da sua juventude e como tais narrativas relacionam-se à sua maneira de consumir. Assim, este trabalho pode contribuir também neste ponto ao analisar o consumo utópico de jovens consumidores que procuram numa época passada, como a dos anos 60 e 70, um ideal de autenticidade sem que esta época tenha sido por eles vivenciada.

No campo gerencial, este trabalho apresenta também uma relevância gerencial ao lançar luz sobre as formas simbólicas que usuários de comunidades virtuais online, como as constituídas no Facebook, utilizam para construir significados culturais em torno do consumo de produtos, serviços e experiências. Mais especificamente, empresas que vendem produtos, serviços e experiências associadas ao rock clássico podem utilizar alguns dos resultados deste trabalho para compreender melhor o processo de construção simbólica entre o que é considerado autêntico pelos fãs de rock e aquilo que é percebido como inautêntico. Como trata-se de um nicho de mercado, sugere-se que as ações de marketing direcionadas a este envolvam uma estratégia de comunicação altamente personalizada e que leve em consideração os valores, linguagem e significados compartilhados pelo grupo. Como o grupo expressa forte rejeição à ideia de mercado e mercantilização, de um modo geral, sugere-se que empresas interessadas neste nicho evitem ao máximo serem percebidas como inteiramente interessadas no lucro. Algumas alternativas para evitar tal percepção seriam: a) a criação de conteúdo valioso para o fã de rock, visto que estes valorizam o conhecimento original como aspecto de autenticação e legitimação de membros; b) a seleção e preparação 
de uma força de vendas "insider" desse nicho, de modo que esta seja composta por pessoas que vivenciam os valores, ritos e crenças da comunidade; c) promover ações que valorizem os membros do nicho com conhecimentos e produtos (como coleções, por exemplo) desejados e admirados pelo restante da comunidade, como forma de utilização da hierarquia de status existente; e d) criar ambientes e experiências que permitam ao fã de rock entrar em contato com o passado idealizado como autêntico, principalmente em se tratando de jovens fãs de rock. Acredita-se que ações desta natureza possam criar valor para o fã de rock e para empresas que buscarem atender a este nicho, de modo a isolar a percepção de interferência da razão instrumental do mercado.

Por fim, sugere-se a investigação da construção de significados de autenticidade por fãs de rock em outros contextos, como o "mundo real" e outros países, por exemplo. Outra sugestão de estudo seria a investigação exclusiva de como jovens fãs de rock constroem significados de autenticidade. Outro ponto que também pode ser relevante é o papel dos fãs de rock mais velhos na construção de uma visão romântica do rock clássico e dos anos 60 e 70. Sugere-se também a realização de estudos em outros contextos de consumo relacionados ao passado junto a consumidores jovens. Lugares, produtos antigos e experiências associadas ao passado e que são considerados autênticos por jovens são um exemplo de possíveis contextos a serem investigados nesse sentido.

\section{REFERÊNCIAS}

BARBOSA, L.; CAMPELL, C. O consumo nas ciências sociais. In: BARBOSA, L.;

CAMPELL, C. (Eds.). Cultura, consumo e identidade. Rio de Janeiro: FGV, 2006. p. 2146.

BAUMAN, Z. Vida para consumo. Rio de Janeiro: Zahar, 2008.

BELK, R. W. Possessions and the extended self. Journal of Consumer Research, v. 15, n. 2, p. 139-168, 1988.

BELK, R. W. The role of possessions in constructing and maintaining a sense of past.

Advances in Consumer Research, v. 17, p. 669-676, 1990.

BELK, R; FISCHER, E; KOZINETS, R. V. Qualitative consumer \& marketing research. London: Sage, 2013.

BELK, R. W; WALLENDORF, M; SHERRY, J. The sacred and the profane in consumer behavior: theodicy on the odyssey. Journal of Consumer Research, v.16, p. 1- 38, 1989. 
BEVERLAND, M. B; FARRELLY, F. J. The quest for authenticity in consumption: consumers' purposive choice of authentic cues to shape experienced outcomes. Journal of Consumer Research, v. 36, n. 5, p. 838-856, 2010.

CAMPBELL, C. A ética romântica e o espírito do consumismo moderno. Rio de Janeiro: Rocco, 2001.

CHACON, P. O que é rock. São Paulo: Brasiliense, 1982.

DIAS, V. N. D; RONSINI, V. V. M. O consumo de música regional como mediador da identidade. Ponto-e-vírgula, v. 4, p. 344-357, 2008.

GOULDING, C. The commodification of the past, postmodern pastiche, and the search for authentic experiences at contemporary heritage attractions. European Journal of Marketing, v. 34, n. 7, p. 835-853, 2000.

GOULDING, C. Romancing the past: heritage visiting and the nostalgic consumer.

Psychology \& Marketing, v. 18, n. 6, p. 565-592, 2001.

GRAYSON, K; MARTINEC, R. Consumer perceptions of iconicity and indexicality and their influence on assessments of authentic market offerings. Journal of Consumer Research, v. 31, p. 296-312, 2004.

HIGSON, A. Nostalgia is not what it used to be: heritage films, nostalgia websites and contemporary consumers. Consumption Markets \& Culture, v. 17, n. 2, p. 120-142, 2014. HOLT, D. B. Why do brands cause trouble? A dialectical theory of consumer culture and branding. Journal of Consumer Research, v. 29, n. 1, p.70-90, 2002.

KOZINETS, R. V. Click to connect: netnography and tribal advertising. Journal of Advertising Research, v. 46, n.3, p. 279-288, 2006 a.

KOZINETS, R. V. Netnography 2.0. In: BELK, R. W. (Ed.). Handbook of qualitative research methods in marketing. Cheltenham: Edward Edgar, 2006b. p. 129-142.

KOZINETS, R. V. On netnography: initial reflections on consumer research investigations of cyberculture. Advances in Consumer Research, v. 25. p. 366-371, 1998.

KOZINETS, R. V. Utopian Enterprise: Articulating the Meanings of Star Trek's Culture of Consumption. Journal of Consumer Research, v. 28, p. 67-88. 2001.

KOZINETS, R. V. Netnography: doing ethnographic research online. London: Sage, 2010 .

LEIGH, T. W; PETERS, C; SHELTON, J. The consumer quest for authenticity: the multiplicity of meanings within the MG subculture of consumption. Journal of the Academy of Marketing Science, v. 34, n. 4, p. 481-493, 2006.

LÉVY, P. Cibercultura. São Paulo: Editora 34, 1999. 
LEWIN, P.; WILLIANS, J. P. The ideology and practice of authenticity in punk subculture. In: VANINNI, P; WILLIANS, J. P. (Eds.) Authenticity in culture, self, and society. Burlington: Ashgate, 2009. p. 65-84.

MACCANNEL, D. Staged Authenticity: arrangements of social space in tourist settings. The American Journal of Sociology, v. 79, n. 3, p. 589-603, 1973.

MACLARAN, P; BROWN, S. The center cannot hold: consuming in the utopian marketplace. Journal of Consumer Research, v. 32, n. 2, p. 311-323, 2005.

MORGAN, G. Paradigmas, metáforas e resolução de quebra-cabeças na teoria das organizações. In: CALDAS, M; BERTERO, C. O (Coord). Teoria das Organizações. São Paulo: Atlas, 2007. p. 12-33

MUNIZ, A. M; O’GUINN, T. C. Brand Community. Journal of Consumer Research, v. 27, n. 4, p. 412-432, 2001.

PEREIRA, S. J. N; AYROSA, E. A. T. Between two worlds: an ethnographic study of gay consumer culture in Rio de Janeiro. Brazilian Administration Review, v. 9, n. 2, p. 211$228,2012$.

RIBEIRO, F. V. Entre os extremos do consumo: fãs, colecionadores e aficionados. Tese de Doutorado em Ciências Sociais, Pontifícia Universidade Católica de São Paulo, São Paulo, 2005.

SCARABOTO, D; FISCHER, E. frustated fatshionistas: an institutional theory perspective on consumer quests for greater choice in mainstream markets. Journal of Consumer Research, v. 39, p. 1234-1257, 2013.

SCHOUTEN, J; MCALEXANDER, J. H. Subcultures of consumption: an ethnography of the new bikers. Journal of Consumer Research, v. 22, n.1, p. 43-61, 1995.

TAYLOR, C. A Ética da autenticidade. São Paulo: É Realizações, 2011.

THOMPSON, C. J. Interpreting consumers: A hermeneutical framework for deriving marketing insights from the text of consumers' consumption stories. Journal of Marketing Research, v. 34, n.4, p. 438-455, 1997.

THOMPSON, C. J; RINDFLEISCH, A; ARSEL, Z. Emotional Branding and the strategic value of the doppelgänger brand image. Journal of Marketing, v.70, n.1, p. 50-64, 2006. VANINNI, P.; WILLIANS, J. P. Authenticity in culture, self, and society. Burlington: Ashgate, 2009.

WANG, N. Rethinking authenticity in tourism experience. Annals of Tourism Research, v. 26, n. 2, p. 346-370, 1999. 
YAZICIOGLU, E. T. Contesting the global consumption ethos: reterritorialization of rock in Turkey. Journal of Macromarketing, v. 30, n. 3, p. 238-253, 2010. 